\title{
Inspiration of Successful Experience of U.S. and European Enterprises Leveraging Sports Marketing on “Going Global” of Chinese Enterprises
}

\author{
Hailin Lu \\ School of Sports Science, Nantong University, Nantong 226019, China
}

\begin{abstract}
With the globalization of sports event, sports marketing has become a promotion strategy of more and more enterprises. Chinese enterprises have also gradually realized the commercial value of sports. Sports marketing has been paid increasing attention by enterprises as a means of brand promotion. Through the analysis of the sports marketing experience of five representative enterprises, Intel, Coca-cola, Herbalife, Omega and Babycare, this paper explores their successful experience, so as to assist Chinese enterprises in "going global" with the help of sports marketing.
\end{abstract}

Key words: U.S.-EU famous enterprises, sports marketing, experience, inspiration.

The advanced multimedia technology has brought the contemporary stormy sports events into every corner of the world, which is attracting more and more attention. Chinese enterprises have also gradually recognized the commercial value of sports. Sports marketing has been paid increasing attention by enterprises as a means of brand promotion. However, currently the sports marketing of domestic enterprises lacks thorough theories and effective experience, thus having a poor marketing performance. Throughout the history of famous enterprises both at home and abroad, there are cases succeeding in using sports marketing, which are represented by Intel, Coca-cola, Lenovo, Samsung, Herbalife, Babycare, Nike and Omega. Through the analysis of their successful experience, some universal sports marketing rules can be concluded, which is conducive to improving the sports marketing level of Chinese enterprises.

\section{The General Situation of Sports Marketing of Foreign Famous Enterprises}

\subsection{Intel: Make the Best Use of All Sports Events}

Intel is the world largest chip manufacturer. Now, it

Corresponding author: Hailin Lu, M.S., lecturer, research field: sports economy and industry. has expanded its business to the field of microprocessor, chipset, board card, system, software and so on. Its subsidiaries have been set up in many countries around the world, with a staff number of near 80,000. In addition to co-marketing, Intel has also launched a variety of sports marketing activities.

1.1.1 Intel and the Olympic Games- "Chip Makes All the Olympic Equipment Function Well"

In the Olympic Games of 2008 held in China, Lenovo became the direct sponsor of Olympic Games and deployed its own Olympic strategy, which mainly provided the experience mode for consumers and sponsored the Olympic Games. Lenovo set up many Olympic experience areas in the Olympic venue, providing the information of the Olympic Games and other useful information, while by virtue of the business cooperation with Lenovo, Intel also moved its brand to the experience area. The brand mark of Intel which provided the major chip had also appeared during the Olympic Gamesfor a long time. Later at the end of July 2008, Lenovo opened the experience pavilion in Beijing Olympic Park, which expanded the experience area and became closer with the Olympic Games. What's more, all the equipment displayed adopted Intel processor technology and it also invited 
the Intel's vice president and general manager of China, Yang $\mathrm{Xu}$, to deliver a speech. He proudly introduced that all the technology equipment sponsored to the Olympic Games were set up based on the technology such as the chip. He was very glad that the technology of Intel could serve the Olympic Games and contribute and boost the morale of Olympic Games in the stable and continuous usage state. Meanwhile, it had won the consumers' understanding and trust of Intel.

1.1.2 Intel and F1 - the "boom" of racing technology

On September 26, 2006, Intel brought the racing car to us relying on its own technology, making BMW Sauber performing in Beijing a reality. This activity was not only an exhibition of the passion and charm of sports but also a good display of brand promotion and product experience, which promoted the Core Duo processor well.

1.1.3 Intel and e-sports_-giving a soaring "chip" to e-sports

Intel had cooperated with e-sports in 2005 and built a strategic partnership. The world-famous manufacturer had provided huge supports for the game and ingrained its technology and brand into the mind of numerous players.

1.1.4 Intel and European Cup-Ultrabook's enjoyment of "chip"

Intel had also been actively involved in the European Cup of June 2012. Besides, joining hands with Sina Sports, they set up the criticism column of the Battle of Europe, which is another close combination of Intel and sports.

1.1.5 Intel and the London Olympics—-super "chip" Podcast

On July 27, 2012, during the London Games, Intel joined hands with Tencent Wechat and broadcast the Super Star Podcast, which is the first mobile voice broadcasting based on mobile internet terminal covering several hot words such as star, Olympic, voice, interaction and new media, which was another bold and innovative attempt of Intel combining with sports events. A series of marketing strategy boosted the rapid development of various business of Intel, making it one of the world's top 500. It could be regarded as a company which monopolized and led the transistor technology, and created the myth of transistor industry-Moore's law [1].

\subsection{Coca-Cola: World's Top Brand with the Longest} History of Sports Marketing.

Coca-Cola is the one of the enterprises that first recognize the enormous commercial value of sports, and make sports marketing one of the long-term and systematic in the world. It began sponsoring the American baseball game since 1907, and since the Amsterdam Olympics of 1928, it started to become the sponsor of the Olympic Games. Besides, it is the long-term partner of World Cup Soccer Tournament and NBA, and an enthusiastic sponsor of many other international and American sports organizations and competitions. Coca-Cola is best at the Olympic marketing, and as a long-term partner of the Olympic Games, it has been continuously sponsored Olympic Games for more than 80 years, and signed a cooperation agreement with the International Olympic to 2020. Adhering to the Olympic marketing strategy of "Olympic spirit, brand connotation and consumers", Coca-Cola has successfully integrated the Olympic spirit into the brand culture completely. It is one of the most successful companies of Olympic marketing recognized by the world. [2]

\subsection{Herbalife: The Official Nutrition Sponsoring} Company of Many World Championship Teams.

Herbalife has sponsored more than 100 top athletes, sports teams and sports events. It has actively sponsored, supported and participated in sports events around the world. Herbalife has been involved in a lot of competitions from the world-famous Triathlon and bicycle race to local boat race and sports championships, which vigorously promotes the health undertakings. The financial data of Herbalife in recent years have showed that the performance has an obvious 
growth momentum, and its position in China market is rising. In 2013, Herbalife's annual total sales (including tax) of China amounted to 40 billion yuan, with a year-on-year growth of more than $60 \%$. Its first product "Almighty Nutritious Breakfast" accounted for $70 \%$ of market returns of Herbalife, which was the healthy weight management series product. According to market consulting statistics, Herbalife accounted for more than $91 \%$ market share of the meal market. Herbalife's achievement in the field cannot be separated with its vigorous promotion of sports event. If it made no effort in various sports activities, it would not have today's achievement. [3]

\subsection{OMEGA: Displaying the Advanced Technology of Product through the Olympic Platform.}

As the official timekeeper, in the 70 years of cooperating with the Olympic Games, Omega has always provided extremely accurate timing service for the Olympic Games, made an indelible contribution to the development and innovation of Olympic timing technology, and directly promoted the transformation of the Olympic Games. For example, in the Mexico City Olympic Games of 1968, the utilization of touch pad of OMEGA had refrained the players from pushing the stopwatch in the terminal point as before personally. And the other epoch-making progress is that the Omega timing system connects the starting gun, loudspeaker and starting signal together, with a timing accuracy of 1/1,000 second, which also declares that the differences between the timekeeper and judge have eventually became the history [4]. Through the Olympic platform, OMEGA shows the advanced technology of product and the long history of brand to the whole world, greatly enhancing the brand value.

\subsection{Babycare: Having a Date with WTA.}

After the cooperation with the WTA for 7 years, USANA has signed cooperation contract and upgraded the cooperation content with the world leader of women's professional sports. WTA is the management organization of world's women's professional tennis and also the world's famous women's sports organization. Currently, over 2,500 registered players from 92 countries have participated in the tournament. 54 races and 4 Grand Slam tournaments have been organized in 33 countries around the world, and the total prize of the tournaments is more than 180 million dollars. The partnership between USANA and the WTA has been considered to be perfect since 2006, which has been designated as the only nutritional supplements provider by WTA authority by virtue of its excellent product quality and provided the NSF and HFL tested nutritional supplements for over 160 WTA players. As a pioneer of the industry, USANA first proposes the athletes assurance program. With strict assurance, it dispels the athletes' concerns, and adds new advantages for itself to be the sole provider of global official nutrition for WTA. It is only a part of USANA's brand strategy to become platinum sponsor of China Open, but it is obvious that it has made great achievement, and USANA has been strongly exposed and won the brand effect through the cooperation with WTA [3].

\section{Successful Sports Marketing Experience of Foreign Famous Enterprises}

Although these companies are located in different countries and belong to different industries, and they adopt different sports marketing strategies and have different experiences, some common rules can still be concluded from their successful experience as follows:

(1) Focus on the sustainability and long-term nature of sports marketing; (2) focus on the interactive nature of sports marketing; (3) focus on the study of integrating degree of sports elements and brand elements; (4) focus on the following commercial development of sports resources; (5) focus on choosing the sports platform that can boost the publicity; (6) focus on the consistency of sports marketing range and brand target market. 
All of the above are some successful experience of sports marketing of some large enterprises, but we can sum up some general marketing rules, which is conducive to improving the overall level of sports marketing of Chinese enterprises obviously. However, in addition to learning the successful experience of foreign typical enterprises, we should take into consideration the current situation in China, and make concrete analysis of specific issues. At present, the domestic sponsoring market of sports event is developing unevenly, which not only exists in various sports events but also in the competition of different levels in the same sports event.

\section{How Do Chinese Enterprises "Go Global"}

In summary, although sports events sponsorship has provided opportunities for enterprises, improved the cost efficiency of enterprises, and brought huge economic and social benefits for enterprises, but it has also contained great challenges. In addition to learning the experience of foreign successful enterprises, the sponsoring enterprises should also combine the special condition of China, draw the experience and lessons of enterprises with poor marketing performance at home and abroad, and actively avoid risks in sports marketing.

\subsection{Strengthen the Analysis of Target Market}

One of the potential risks of target market is the integrating degree between corporate brand and sponsorship projects. For example, whether there is close connection between the brand spirit and corporate product image with the spirit reflected by the sports events. If they are not related, it may lead to fuzzy brand image, achieving the opposite marketing effect. The other risk is whether the target audiences of the products are consistent with the objects faced the sponsored sports, which is reflected in the concern extent of audiences and the media on sports events, the participation of target customers and their attitude on the sports events. Enterprises should do market research well, understand the situation of sports audiences and the sponsorship requirements of sports events, have a definite object, and formulate the feasible, targeted, effective and prospective marketing scheme of sports sponsorship, thus achieving good marketing effect. For example, this year ZTE, as the foreign magnate in the world, is very outstanding in European and American events, and the keyword of its sports marketing is localization. Take American market as an example, ZTE enjoys a large sales in the United States. In 2015, it sold 15 million mobile phones, occupied the second largest market share of $20 \%$ in the market of contract phone and the third largest market share of $12 . \%$ in the Android Market. It can be seen that ZTE can display itself through the basketball games every week and television replay by sponsoring the top team of NBA. Till the stage of the finals, its exposure has increased, and the sports marketing strategy in the local has achieved great success, which will build benign interaction with the spread of ZTE brand in domestic. While different from ZTE, HUAWEI has lost in the management of localization. As it can be seen, HUAWEI has also paid huge sums to invite Messi as the spokesperson to promote the brand on behalf of it globally. But the difference between the two is that HUAWEI mainly sells phones in China, while Messi has limited audiences in China certainly. Therefore, the intention of sports marketing of HUAWEI is more likely to overwhelm the Chinese users by virtue of world-famous star. In the view of insider, the path of HUAWEI has a clear bottleneck, which can attract the attention of people but may not please the target users in China [6].

\subsection{Identify the Market Positioning and Target} Customers

Enterprises should identify the essence of its own brand, the target audiences of the product, value orientation of the brand before sponsoring, and select the sponsoring objects according to its scale, strength, 
brand position, sponsorship objects, market positioning, target audiences scope, scale and funding, which should not make sports sponsorship blindly. Not all enterprises can obtain good social and economic benefits through sponsoring sports events, and a lot of enterprises do not achieve good marketing results, and even bear losses. According to the 2008 Olympic Marketing Report issued by China Brand Research Institute, up to July 21, 2008, 90\% of sponsoring enterprises of Beijing's Olympic sponsorship had not been successful, and only $10 \%$ of the enterprises had achieved better marketing effect. Different enterprises choose different marketing strategies and scopes. The large enterprises who have a certain scale and strength and expect to be world famous brands can choose international or global sporting events as the marketing platform, such as the World Cup and Olympic Games; some small enterprises or those who expect to enter a regional market can choose regional or local events to market such as the college sports meetings and college students leagues. Smaller companies can also co-sponsor a sports event with many enterprises, which can diverse the risk of corporate sponsorship, and achieve good marketing results at the same time. When sponsoring the sports, the enterprises should set proper goal, and find the suitable marketing platform. In recently years, OPPO smart phone has vigorously promoted the globalization, but it lacks momentum in the sports marketing. The mobile phone targets at young fashion groups, and it attracts the young users with the help of advertising effect of celebrity. This year in the European Championship, it hoped to influence Chinese fans by sponsoring Barcelona team, but because the team was eliminated in April this year, so the effect of the advertising marketing war was poor [6].

\subsection{Grasp the Integrating Point between the Enterprises and Sponsored Activities}

The cooperation between enterprises and sports events is a double-edged sword. If the enterprise's brand is not outstanding enough, it will be submerged in the halo of the prestigious event. For example, usually we only remember the excellent performance of athletes in the arena, but rarely care about which enterprises sponsor the events. When marketing, enterprises should grasp its integrating point with the sponsored sports, integrate the enterprise resources, and merge the sports culture into the corporate culture and brand culture, thus achieving a win-win situation between the enterprise and the sports organization. The activities that enterprises sponsor should be closely related with the corporate image and product, with a certain degree of affinity. Besides, the culture of sports spirits reflected by the activities should be consistent with the corporate culture and brand culture. The sports culture should be integrated into all aspects of business, thus achieving the resonance of the enterprises and consumers. It had better make that as long as the audiences see or refer to this activity, it will remind them of the sponsored enterprises and their products. For example, by virtue of the platform of Asian Games, the product carrier and a series of integrated transmission activities, TCL has enabled more people to appreciate the fashion and healthy lifestyle and proactive and self-fulfilling life attitude. Besides, it has integrated the passion, joy and aggressiveness Asian Games spirit into its brand, making the Asian Games the emotional bond between TCL and the target audiences, thus further promoting the business growth and making corporate culture more consistent with sports culture [8].

\subsection{Constantly Revise the Marketing Plan and Use Integrated Marketing}

With the change of the market environment, enterprises should make sufficient business evaluation of the sports sponsorship and benefit return, and make timely and corresponding adjustment of the emphasis of sports marketing. Now China is in the period of social and economic transformation, and the social 
values have also changed constantly, so do the consumer demand and consumption levels. Therefore, the sponsors should change the traditional marketing idea, take meeting the consumer demand as the core and constantly adjust the marketing plan according to the market demand. Integrated marketing is a systematic combination of a variety of marketing tools and means, and it makes immediate dynamic revision according to the environment, which is the marketing concept and method for interacting parties to achieve added value in interaction. Sports sponsorship is only one marketing method of enterprise, and in order to produce good marketing communicating effect it must coordinate with other marketing means. Sports event sponsorship is an economic and effective way for enterprises to market and a good platform for enterprises to promote and display themselves, which boosts the enterprises to go global and enter the international market. Through the marketing means of sports sponsorship, enterprises inject the sports culture into their own products or services, integrate the enterprise resources and produce the synergistic effect. They expand their business by sponsoring sports events, promote their brands and obtain greater opportunities for business expansion.

\section{References}

[1] Li, Q. Q. 2013. "The Comparative Analysis of Sports Marketing Strategy between Samsung and Intel.” Master's thesis, East China Normal University.

[2] Cao, F. H. 2008. "Post-Olympic Era, the Organic Unity of the Brand Tactics and the Brand Strategy." Technology Think Tank 3 (7): 22-4.

[3] Direct sales100. 2016. How Does Direct Sales Giant Achieve the Win-Win of Brand and Performance by Sponsoring Sports Events. Accessed June 15, 2016. http://zhixiao100.com.

[4] Yuan, Y. 2008. "Olympic Marketing Password of OMEGA.” China Foreign Investment 6 (4): 78-83.

[5] Fan, L. L. 2006. Samsung and SONY. Beijing: China Economic Publishing House.

[6] Global Network. 2016. Chinese Enterprises Flood to Europe and America Sports Events on the Sports Marketing of Huawei and ZTE. Accessed June 20, 2016. http://w.huanqiu.com/r/MV8wXzkwODE3MzlfNDhfMT Q2Njc4MzgyMA==?plg_nld=1\&plg_uin=1\&plg_auth=1 $\& p l g \_n l d=1 \& p l g \_u s r=1 \& p l g \_v k e y=1 \& p l g \_d e v=1$

[7] China Brand Research Institute. 2008. Olympic Marketing Report: $90 \%$ Sponsors Fail before the Match. Accessed June 15, 2016. http://money.163.com/08/0802/00 /4IA4GKQ4002524SC.html.

[8] NetEase Finance. 2016. TCL Liang Qichun: The Asian Games Marketing Is a Long-Term Strategy Rather than a Promotion. Accessed June 10, 2016. http://money.163.com/09/0702/21 /5D8DHVG800253FHA.html. 